\title{
Hypertensive disorders in twin pregnancy
}

\author{
Ana DUMINICA-TURCU ${ }^{1}$, Nicolae GICA ${ }^{1,2}$, Brindusa Ana CIMPOCA-RAPTIS ${ }^{1}$, \\ Anca Marina CIOBANU ${ }^{1,2}$, Corina GICA $^{1}$, Radu BOTEZATU ${ }^{1,2}$, \\ Gheorghe PELTECU ${ }^{1,2}$,Anca Maria PANAITESCU ${ }^{1,2}$ \\ ${ }^{1}$ Filantropia Clinical Hospital, Bucharest, Romania \\ 2"Carol Davila" University of Medicine and Pharmacy, Bucharest, Romania
}

\begin{abstract}
-
Hypertensive disorders such as gestational hypertension, preeclampsia, eclampsia and HELLP syndrome are one of the most common pregnancy-associated entities that imply substantial maternal-fetal mortality and morbidity. When hypertensive disorders are associated with a multiple pregnancy, the outset is established sooner, with a rapid evolution and a more severe development. Although, the pathophysiology of hypertensive disorders is not fully understood, there are several risk factors that could be identified. A multiple pregnancy implies additional risks due to specific features: larger or multiple placentas, failure of the uteroplacental unit to uphold the natural development of multiple fetuses or elevated risk of abnormal placental site. Hypertensive disorders include complications that are common for both single and multiple pregnancies, complications such as kidney failure, liver dysfunction, neurological or hematological malfunction, among others. Maternal features, including mean arterial blood pressure, uterine artery pulsatility index and blood levels of PAPP-A and/or PlGF could be determined at an early age and used as screening methods.
\end{abstract}

Keywords: hypertensive disorders, twin pregnancy, preeclampsia, HELLP syndrome

\section{BACKGROUND}

Pregnancy represents an eventful experience in a woman's life, with important cardiovascular and hemodynamic alterations in order to sustain fetal and placental growth. An imbalance of the hemodynamic changes might lead to disorders such as hypertension or preeclampsia, among others. Germain and al analysed the axiom that stated that endothelial dysfunction could be a starting point for adverse outcomes during pregnancy or injurious cardiovascular events at an older age [1]. Preeclampsia is defined as the recent establishment of hypertension after 20 weeks of pregnancy, oftentimes associated with proteinuria, but not exclusively, as other risk factors might be present in the absence of proteinuria [2] as they are noted in table 1.
Per contra, gestational hypertension develops in a formerly normally blood pressure woman, after 20 weeks of gestation and implies a systolic blood pressure of minimum $140 \mathrm{mmHg}$ with or without diastolic blood pressure of a minimim $90 \mathrm{mmHg}$ [3], while preeclampsia develops when systolic blood pressure exceeds systolic blood pressure of $160 \mathrm{mmHg}$ and diastolic blood pressure of $110 \mathrm{mmHg}$ [4]. Proteinuria at the time of pregnancy is characterized by a minimum of $300 \mathrm{mg} / \mathrm{dl}$ of protein in a daily urine acquisition or a minimum proportion of protein-to-creatinine of 0.3 , dipstick urinalysis accounted as an alternative method when rapid results are needed, $2+$ being taken into consideration as a positive result [5]. As above-mentioned, gestational hypertension is established in a formerly normally blood pressure woman, after 20 weeks of gestation 
with a systolic blood pressure of minimum $140 \mathrm{mmHg}$ with or without diastolic blood pressure of a minimim $90 \mathrm{mmHg}$. As Sibai noted, proteinuria or organ deterioration might occur in up to half of the pregnant women diagnosed with gestational hypertension, especially when the diagnosis is established before the third trimester of pregnancy [6]. Accounted as a severe form of preeclampsia, implying elevated maternal mortality and morbidity, HELLP syndrome is defined by hemolysis: lactate dehydrogenase of a minimum $600 \mathrm{IU} / \mathrm{l}$, high liver enzymes more than double of the upper limit and low platelet, beneath $100 \times 10^{9} / \mathrm{I}$ and as Barton noted, it involves a a well-defined management plan, sometimes, after 34 weeks of gestation, implying the need for delivery [7].

TABLE 1. Risk factors of preeclampsia [2]

\begin{tabular}{|l|}
\hline First pregnancy \\
\hline Multiple pregnancies \\
\hline History of preeclampsia in previous pregnancies \\
\hline Carbohydrate metabolism disorders \\
\hline Pregestational hypertensive disorders \\
\hline Autoimmune disorders \\
\hline A high Quetelet index \\
\hline Prothrombotic state \\
\hline Nephropathy \\
\hline Older parous woman \\
\hline Fertility treatments \\
\hline Sleep apnea \\
\hline
\end{tabular}

\section{METHODS}

In order to obtain a systematic literature review, medical databases such as PubMed and Google Scholar were searched, using key words such as hypertensive disorders, twin pregnancy, HELLP syndrome and preeclampsia. The search resulted in over 200 articles for analysis related to the chosen subject, from which only 23 papers were further reviewed and included in the final review.

\section{PATHOPHYSIOLOGY}

Dekker and Sibai studied the hypotheses that involved the etiology of preeclampsia: placental ischemia-increased trophoblast deportation, ischemia leading to endothelial cell dysfunction; very low-density lipoprotein versus toxicity-preventing activity in which non-esterified fatty acids are activated as a result of an elevated energetic expenditure during the pregnant months; immune maladaptation that involves interaction between decidual leukocytes and invading cytotrophoblast in which high rates of cytokines, proteolytic enzymes and free radical species are being discharged; genetic imprinting, implying a single recessive gene or a dominant gene with incomplete penetrance [8].

Physiologically, hypervolemia is a sign of a normal pregnancy, contrasted by hemoconcentration which is associated with hypertensive disorders [9]. Vasospasm is a frequently described event during hypertensive disorders, as a result of the interaction between vasodilators such as nitric oxide and prostacyclin and vasoconstrictors such as thromboxane $\mathrm{A} 2$ and endothelins [10]. Using invasive hemodynamic monitoring, Hankins et al. studied eight primigravid women diagnosed with eclampsia and concluded that hemodynamic status is undoubtedly altered by disparity in fluid management, therefore a proper management should consider constraint of fluid, in order to avoid pulmonary edema [10]. Hematologic changes include thrombocytopenia as a result of platelet activation, aggregation and consumption, hemoconcentration due to vasospasm and hemolysis reflected in high LDH more than $600 \mathrm{IU} / \mathrm{I}$ discharged from erythrocytes [11]. Periportal necrosis is the leading cause of elevated liver enzymes, while LDH might result from ischemic or necrotic tissues, as well as from the destruction of erythrocytes. Hepatic changes during hypertensive disorders are also reflected by an elevation of the bilirubin level or changes in the blood coagulation parameters. A special attention is given to the renal changes that occur in a pregnant woman when hypertensive disorders are diagnosed. Endothelial cells are enlarged, containing a large quantity of fibrils, mesangial cells are expanded and proteins are deposited at the subendothelial level [12]. Tubular permeability is enhanced and it facilitates the passage of albumin, globulin, transferrin and hemoglobin, but tubular reabsorption of calcium in increased. Renal vasospasm leads to oliguria. Uric acid increases in hypertensive disorders due to a high production and reabsorption and diminished excretion in the proximal renal tubules [13].

\section{SPECIFIC FEATURES OF TWIN PREGNANCY}

A multiple pregnancy implies additional risks due to specific features: larger or multiple placentas, placental cluster or failure of the uteroplacental unit to uphold the natural development of multiple fetuses as they are listed in Table 2. Compared to a single pregnancy, a multiple pregnancy can lead to higher rates of hypertensive disorders like preeclampsia, gestational diabetes, preterm birth, intrauterine growth restriction, increases perinatal death or the 
risk of operative delivery or a complicated delivery [14].

TABLE 2. Specific features of multiple pregnancies that can lead to higher complication rates

\begin{tabular}{|l|}
\hline Larger placenta \\
\hline Multiple placentas \\
\hline Placental cluster \\
\hline $\begin{array}{l}\text { Failure of placental unit to uphold natural development of } \\
\text { multiple fetuses }\end{array}$ \\
\hline Substandard placental implantation \\
\hline Elevated risk of abnormal placental site \\
\hline
\end{tabular}

According to the current literature, preeclampsia complicates $2-5 \%$ of all pregnancies and multiple pregnancies are noted to be an autonomous risk factor for hypertensive disorders, 3.50 times higher in dizygotic twins compared to monozygotic twins and 2.61 times higher in the monozygotic pregnancy [15], the risk of severe hypertension being 2-3 times higher in a multiple pregnancy [16]. Hypertensive disorders include complications that are common for both single and multiple pregnancies, complications such as kidney failure, liver dysfunction, neurological or hematological malfunction, uterine placental dysfunction or intrauterine fetal growth restriction. According to Okby et al., a retrospective population-based cohort study comparing maternal and neonatal outcome in IVF vs. spontaneously conceived twins, concluded that preeclampsia is prevailing in IVF twins compared to spontaneous twin pregnancies [17]. There are several risk factors that contribute to the higher incidence of hypertensive disorders: higher childbearing age, high BMI, diabetes, chronic hypertension, antiphospholipid syndrome, chronic kidney disease and lupus erythematosus. In a nested case-control study within the Calcium for Preeclampsia Prevention trial, which involved healthy nulliparous women, the pathogenic role that could lead to endothelial dysfunction was studied and included extreme placental anti-angiogenic factors and tyrosine kinase 1 (sflt1) that have the role to antagonize vascular growth factor (VEGF) and placental growth factor (PIGF) [18].

\section{THE MANAGEMENT OF A MULTIPLE PREGNANCY COMPLICATED WITH A HYPERTENSIVE DISORDER}

The management of a multiple pregnancy complicated with a hypertensive disorder is comparable to the management of a singleton pregnancy and includes prevention using antiplatelet drugs, notably aspirin, Duley and al. concluding that antiplatelet treatment starting at 12 or 16 weeks of pregnancy leads to a $53 \%$ lower relative risk (95\% confidence interval: $35 \%$ to $66 \%$ ) [19]. The antiplatelet treatment determines invasion and migration of trophoblastic cells into the uterine artery, interposing with cytokine generation and promoting the establishment of the angiogenic protein placental growth factor (PIGF), proceeding to the inhibition of apoptosis and early uterine artery remodeling [20]. Regarding the dietary supplements, preeclampsia could be determined by a rich carbohydrate regimen, the inadequacy of protein, iron and other micronutrients, so their supplementation is included in the prevention management therapy [21]. Maternal features, including mean arterial blood pressure, uterine artery pulsatility index and blood levels of PAPP-A and/or PIGF could be determined at an early age and used as screening methods [22]. According to NICE recommendations, preeclampsia, especially diagnosed after 37 weeks of gestation, implies delivery as soon as possible as a curative treatment [23].

\section{CONCLUSIONS}

There is a continuous raise in the age of women who give birth for the first time, thus this feature leading to high rates of assisted reproductive treatment usage and to a higher incidence of multiple pregnancies. Despite these well-known facts, the literature on multiple pregnancies complicated with hypertensive disorders is limited when compared to singleton pregnancies. Undoubtedly, twin pregnancies imply a higher risk factor for hypertensive disorders when compared to a singleton pregnancy. The outset is established sooner, with a rapid evolution and a more severe development. More studies are needed to be implemented in order to successfully identify the proper pathophysiology of hypertensive disorders in a twin pregnancy.

Conflict of interest: none declared Financial support: none declared

\section{REFERENCES}

1. Germain AM, Romanik MC, Guerra I, Solari S, Reyes MS, Johnson RJ, Price K, Karumanchi SA, Valdés G. Endothelial dysfunction: a link among preeclampsia, recurrent pregnancy loss, and future cardiovascular events? Hypertension. 2007 Jan;49(1):90-5.
2. Homer CS, Brown MA, Mangos G, Davis GK. Non-proteinuric pre-eclampsia: a novel risk indicator in women with gestational 
hypertension. J Hypertens. 2008

Feb;26(2):295-302.

3. Report of the National High Blood Pressure Education Program Working Group on High Blood Pressure in Pregnancy. Am J Obstet Gynecol. 2000 Jul;183(1):S1-S22. PMID: 10920346.

4. von Dadelszen P, Payne B, Li J, Ansermino JM, Broughton Pipkin F, et al.; PIERS Study Group. Prediction of adverse maternal outcomes in pre-eclampsia: development and validation of the fullPIERS model. Lancet. 2011 Jan 15;377(9761):219-27.

5. Phelan LK, Brown MA, Davis GK, Mangos G. A prospective study of the impact of automated dipstick urinalysis on the diagnosis of preeclampsia. Hypertens Pregnancy. 2004;23(2):135-42.

6. Sibai B, Dekker G, Kupferminc M. Pre-eclampsia. Lancet. 2005 Feb 26-Mar 4;365(9461):785-99.

7. Barton JR, Sibai BM. Diagnosis and management of hemolysis, elevated liver enzymes, and low platelets syndrome. Clin Perinatol. 2004 Dec;31(4):807-33, vii.

8. Dekker GA, Sibai BM. Etiology and pathogenesis of preeclampsia: current concepts. Am J Obstet Gynecol. 1998 Nov;179(5):1359-75.

9. Pritchard JA, Cunningham FG, Pritchard SA The Parkland Memorial Hospital protocol for treatment of eclampsia: evaluation of 245 cases. Am J Obstet Gynecol.1984 Apr 1;148(7):951-63.

10. Hankins GD, Wendel GD Jr, Cunningham FG, Leveno KJ. Longitudinal evaluation of hemodynamic changes in eclampsia. Am J Obstet Gynecol. 1984 Nov 1;150(5 Pt 1):506-12.

11. Martin JN Jr, Blake PG, Perry KG Jr, McCaul $J F$, Hess LW, Martin RW. The natural history of HELLP syndrome: patterns of disease progression and regression. Am J Obstet Gynecol. 1991 Jun;164(6 Pt 1):1500-13.

12. Spargo BH. Practical use of electron microscopy for the diagnosis of glomerular disease. Hum Pathol. 1975 Jul;6(4):405-20.

13. Svenningsen $P$, Friis UG, Versland JB, Buhl $\mathrm{KB}$, Møller Frederiksen B, Andersen $\mathrm{H}$, Zachar RM, Bistrup C, Skøtt O, Jørgensen JS, Andersen RF, Jensen BL. Mechanisms of renal $\mathrm{NaCl}$ retention in proteinuric disease. Acta Physiol (Oxf). 2013 Mar;207(3):536-45.

14. Stulberg DB, Jackson RA, Freedman LR. Referrals for Services Prohibited In Catholic Health Care Facilities. Perspect Sex Reprod Health. 2016 Sep;48(3):111-7.

15. Ros HS, Cnattingius S, Lipworth L. Comparison of risk factors for preeclampsia and gestational hypertension in a populationbased cohort study. Am J Epidemiol. 1998 Jun 1;147(11):1062-70.

16. Krotz S, Fajardo J, Ghandi S, Patel A, Keith LG. Hypertensive disease in twin pregnancies: a review. Twin Res. 2002 Feb;5(1):8-14.

17. Okby R, Harlev A, Sacks KN, Sergienko R, Sheiner E. Preeclampsia acts differently in in vitro fertilization versus spontaneous twins. Arch Gynecol Obstet. 2018 Mar;297(3):653658.
18. Levine RJ, Maynard SE, Qian C, Lim KH, England LJ, Yu KF, Schisterman EF, Thadhani R, Sachs BP, Epstein FH, Sibai BM, Sukhatme VP, Karumanchi SA. Circulating angiogenic factors and the risk of preeclampsia. N Engl J Med. 2004 Feb 12;350(7):672-83.

19. Duley L, Henderson-Smart DJ, Meher S, King JF. Antiplatelet agents for preventing pre-eclampsia and its complications. Cochrane Database Syst Rev. 2007 Apr 18;(2):CD004659.

20. Panagodage S, Yong HE, Da Silva Costa F, et al. Low-Dose Acetylsalicylic Acid Treatment Modulates the Production of Cytokines and Improves Trophoblast Function in an in Vitro Model of Early-Onset Preeclampsia. The American Journal of Pathology. 2016 Dec;186(12):3217-3224.

21. Goodnight W, Newman R; Society of Maternal-Fetal Medicine. Optimal nutrition for improved twin pregnancy outcome. Obstet Gynecol. 2009 Nov;114(5):1121 1134.

22. Rana S, Powe CE, Salahuddin S, Verlohren $\mathrm{S}$, Perschel FH, Levine RJ, Lim KH, Wenger JB, Thadhani R, Karumanchi SA. Angiogenic factors and the risk of adverse outcomes in women with suspected preeclampsia. Circulation. 2012 Feb 21;125(7):911-9.

23. National Collaborating Centre for Women's and Children's Health (UK). Hypertension in Pregnancy: The Management of Hypertensive Disorders During Pregnancy. London: RCOG Press; 2010 Aug. 